Journal of History Culture and Art Research (ISSN: 2147-0626)

Tarih Kültür ve Sanat Araştırmaları Dergisi

Vol. 8, No. 3, September 2019

\title{
DOI: 10.7596/taksad.v8i3.2185
}

Citation: Guskova, N. V. (2019). An Investigation on Peer Assessment: Teaching Text Summarization in English. Journal of History Culture and Art Research, 8(3), 91-99. doi:http://dx.doi.org/10.7596/taksad.v8i3.2185

\section{An Investigation on Peer Assessment: Teaching Text Summarization in English}

\section{Natalia V. Guskova ${ }^{1}$}

\begin{abstract}
This paper discusses the specifics of using the method of peer assessment in the process of learning a brief text summary in English by the students of non-linguistic specialties. In particular, the effectiveness and expediency of using peer assessment in teaching foreign languages are analyzed by the author. The empirical part of the research was conducted at the National Research University Higher School of Economics (Moscow, Russia), with a group of undergraduate students studying at the Faculty of Economics. The author relied on a well-developed methodological apparatus, with the purpose of obtaining the most accurate and reliable data and conducting an objective analysis. As a result, the author concludes that the method of peer assessment can solve a number of pedagogical problems: increasing responsibility and autonomy of students; providing a deeper understanding of the subject; developing learning skills; stimulating each student to become an active worker and appraiser; developing critical thinking, etc. In addition, the method of peer assessment focuses on the maximum involvement of students in the learning process, which contributes to better learning motivation. More than that, it develops a supportive learning environment, in which our students could feel comfortable and fully trust each other and their teachers. The research results can be used to develop a more effective methodology for teaching foreign languages at non-linguistic specialties, as well as for conducting further research on related topics.
\end{abstract}

Keywords: Peer assessment, Peer review, Teaching English, University students, Non-Linguistic specialty, Analytical skills, Reading competence, Experiment.

\footnotetext{
${ }^{1}$ PhD in History, Associate Professor, National Research University Higher School of Economics, Moscow, Russia. Email: hse_guskova@mail.ru
} 


\section{Introduction}

The contemporary pedagogical science is deeply interested in analyzing how effective a method of peer assessment, especially when it is applied in the process of teaching brief text summaries in English to those university students who are not studying linguistic specialties. First of all, the relevance of this issue is determined by the need to consider problems of forming and developing those abilities in students that can be regularly applied by various cognitive instruments to assess their knowledge levels in the process of learning English. One of such instrument is the method of peer assessment, which allows students to evaluate each other's work solely by themselves, following a set of strict instructions provided by a teacher in advance (Harchenko, 2017, p.87). Second, there is a lack of quantitative research in the contemporary scholarship, which would evaluate the effectiveness of using the method of peer assessment in the process of teaching brief text summaries in English to the students of nonlinguistic specialties.

In addition, high-quality research on this topic would significantly contribute to an array of other close research fields. In particular, there is strong research need to study how English as a foreign language is taught at non-linguistic universities, as well as to analyze the best approaches and practices existing to increase teaching quality and learning outcomes (Moskaleva, 2016, pp.108-109). In other words, we should concentrate our research efforts on finding ways of (a) improving both teaching and learning processes and (b) developing teaching and studying approaches, which would increase students' motivation in acquiring a foreign language and provide effective learning outcomes. More than that, it is necessary to achieve a more effective learning process, which would also focus not only on mastering a certain amount of knowledge, but also on developing a student's personality, cognitive and creative abilities.

Consequently, the research presented in this paper takes into account all those larger perspectives described above and significantly contributes to the existing body of knowledge by providing a standalone empirical case.

\section{Literature review}

While reviewing the published sources on the issues under consideration, one could note that they address a number of key research areas. First of all, different systems for evaluating students' educational activities are analyzed by Anufrieva (2002), Bojko (2012), Butakova (2006), Falchikov and Boud (2007), Krasnoborova (2010), Krasnova (2003), Larionova (2011), Zhurko (2010), and a number of other researchers and practitioners. Various issues of analyzing textual materials within a framework of conducting an assessment of students in higher educational institutions are covered by Deller and Price (2007), East and Keson (2010), Facione and Facione (1994), Hedge (2007), Rea-Dickins and Germaine (2003), as well as many others. Certain aspects of peer assessment in the process of teaching students are considered by Dacun (2015), Dacun and Kopylov (2018), Harchenko (2017), and Walsh (2014). 
Of great interest is the paper written by Belyaeva (2013), in which she identifies a set of specifics of the method of peer assessment and considers it as an integral part of the so-called "communicationoriented technology of teaching a foreign language" in a non-linguistic university. In particular, this method has a number of undoubted advantages. In general, it allows one to determine the level of analytical skills, to evaluate products of students' cognitive activities, to analyze the impact of selfreflection and self-study of students (Belyaeva, 2013, p.22). Also, the author presents a comprehensive technology for applying "peer assessment" (or "peer review") methods in the process of learning a foreign language. Foreign researchers also appreciate the value of peer assessment in the process of teaching university students. For example, Carless (2015) reveals the important role of this type of assessment in the framework of "Learning Oriented Assessment" (LOA). This is a "peer assessment" teaching technology which implies (a) providing students with the knowledge and (b) then applying an expert evaluation conducted by students themselves. Thus, these students are deeply involved in providing feedback on the results of their own assignments.

In sum, the previously developed body of scholarship contextualizes our research problems and serves as an indispensable source of valuable insights for this experimental research. At the same time, there is a clear gap existing in this body of knowledge. In particular, I would like to note that from the perspective of efficiency, the problem of using the method of mutual evaluation in the process of teaching English to students of non-linguistic specialties has not been fully studied. Ultimately, this fact has determined my interest in this issue.

\section{Research Design}

The gap existing in the literature and the urgent need to study the aforementioned research problems determined the goal of this research, as well as its research subject. In particular, the subject of my research is the use of the method of peer assessment in the process of teaching brief text summaries in English. The research purpose is to experimentally identify the effectiveness of applying the method of peer assessment in the process of teaching text summaries in English to the students of nonlinguistic specialties. This would allow us to present specifics of our research problems in general, which are associated with the study of a foreign language, as well as to suggest certain ways to solve them. The research results can be used to develop a more effective methodology for teaching foreign languages, as well as for further research on this and related topics.

The research methodology is based on the principles of descriptive, comparative, typological, and statistical methods. In particular, I analyzed the empirical data collected with the use of statistical methods, making it possible to obtain the most accurate and reliable data. It consists of statistical observations, summarization, and data grouping. More than that, the research methodology includes the following: calculation of generalized indicators (high, medium, and low levels), statistical distributions, sampling methods, correlation and regression analyses (Den, 2012, pp.118-119). In other words, the method of statistical research (applied in this paper) is aimed at studying the results of students' educational and practical activities in the process of learning a text summary in English. Also, the method is aimed at analyzing the raw data on questioning and testing, as well as on monitoring 
individual achievements, etc. In addition, the research methodology used in this paper makes it possible to determine a competency level with the criteria and indicators that characterize the components of communicative competence and serve as a guide for objectively determining its level.

\section{Results and Discussion}

Peer assessment is a method of pedagogical work that allows students to act as experts in assessing the educational activities of their colleagues. The word "peer" has the following meanings: level, equal (in position, ability), same age, coeval. In addition, this term refers to equal participation in a network, which implies providing services to other participants and using their services themselves. In other words, this is all about participation in the distribution within file-sharing networks (Salder, 2006, p.5; Siemens, 2009, p.204). Probably, the term "peer assessment" received a new, modern interpretation in this sense, and it began to be actively used in distance education, particularly in mass open online courses. As part of this training, each student becomes a "teacher" for other students. Accordingly, such an organization of training shifts some teachers' duties to their students. In this case, a teacher him/herself determines the impact of peer assessment on the overall learning outcomes (Krasnova, 2003, p.46), formulates recommendations and criteria on the basis of which students evaluate learning activities of their fellow students, establishes a "weighting" systems applied to results of peer assessment in the form of final scoring, etc.

As part of applying the method of peer assessment in the process of learning a brief text summary in English, various forms of evaluation and their combinations can be used:

- Peer commenting: expressing someone's own opinion in the form of recommendations, wishes, reasoning on a topic, or as a refutation addressed to a student; it is used in assessments for students, especially when it is difficult to formulate clear assessing criteria; it also suggests a mandatory response to the commenting author;

- Peer review: a detailed and reasoned comment in the form of a review, compiled on the basis of criteria set by a teacher for assessing responses from students; it suggests a mandatory answer to the review;

- Peer assessment: scoring in accordance with the methods of assessment proposed by a teacher; a response is possible, but it is not required.

In practice (in the process of teaching a brief text summary in English), mixed methods of assessment are most popular, combining those tests and peer-to-peer evaluations that effectively complement each other (Arlashkina, 2018, p.133). In turn, this allows a teacher to solve a number of tasks, in particular the following: developing skills of systematization and generalization of the studied material; motivating to learn more about course materials; stimulating responsibility in students for their own learning; developing critical thinking; increasing cognitive activity; developing cooperation skills, etc. In addition, the method of peer assessment, if compared with other methods, is characterized by the high speed of data acquisition, simplicity of organization, possibility of reaching large groups, and relatively low costs. In addition, peer assessment provides opportunities for fast feedback and 
introduces an element of creativity into the whole learning process. Thus, peer assessment becomes a necessary method of work for teaching approaches to and techniques of text summarization to students.

In order to identify the effectiveness level of using the method of peer assessment in the process of teaching techniques of summarizing brief texts in English to the students of non-linguistic specialties, as well as generally examining specifics of the problems associated with learning a foreign language, an experimental study was conducted at the Faculty of Economics of the National Research University Higher School of Economics (Moscow, Russia). The empirical material obtained in the research process was processed on a personal computer using the software system "Statistics" for Windows. In the course of my analysis, peculiarities of using peer assessment for teaching university students were considered. Then I summarized and generalized the results obtained, which made it possible to identify the advantages of this method and conditions for its implementation in the practice of teaching economic disciplines.

The experimental study was made with two groups of students of the National Research University Higher School of Economics. A total of 85 students took part in the research. In the first group, a method of peer assessment was used in the process of learning English (periodically in the Spring semester), and it was not used in the second group.

The experiment consisted of two stages. At the first stage, I worked with the first group of students (43 people). In the process, the group was divided into 7 subgroups of 5-7 people. Each subgroup was provided with a text in English. It was necessary to familiarize themselves with that text, and then write its summary on special numbered sheets (without specifying their names and surnames). After this part of the assignment was completed, these students were asked to transfer their brief presentations for peer review to other students in different subgroups participating in the experiment. At the checking stage, all students were guided with an evaluation sheet with certain criteria $(5-$ highest score, 1 - lowest score). Upon completion of the assessment work, the students received questionnaires aimed at identifying their attitudes toward the very method of peer assessment.

At the second stage, work was carried out with the second group of students ( 42 people); in the process of work, the group was also divided into 7 subgroups of 5-7 people. The second group students were given a similar task: after reading a text in English and writing its summary, they were also asked to transfer their work to students of other subgroups, evaluate the work made by others, and fill out a questionnaire.

After completing the experiment, the following results were identified. In the first group, the majority of assessments received 4 points from the teacher (63.6\%). This suggests that the gave high scores, as a rule, while trying to more objectively evaluate the work performed by other participants. (The last statement is supported by the indicated deviation of student and teacher's assessment indicators less than $6 \%$ ). A total of 5 points was given to $26.4 \%$ of all assignments, 3 points $-10 \%, 2$ and 1 point - not identified (Figure 1, Table 1). 


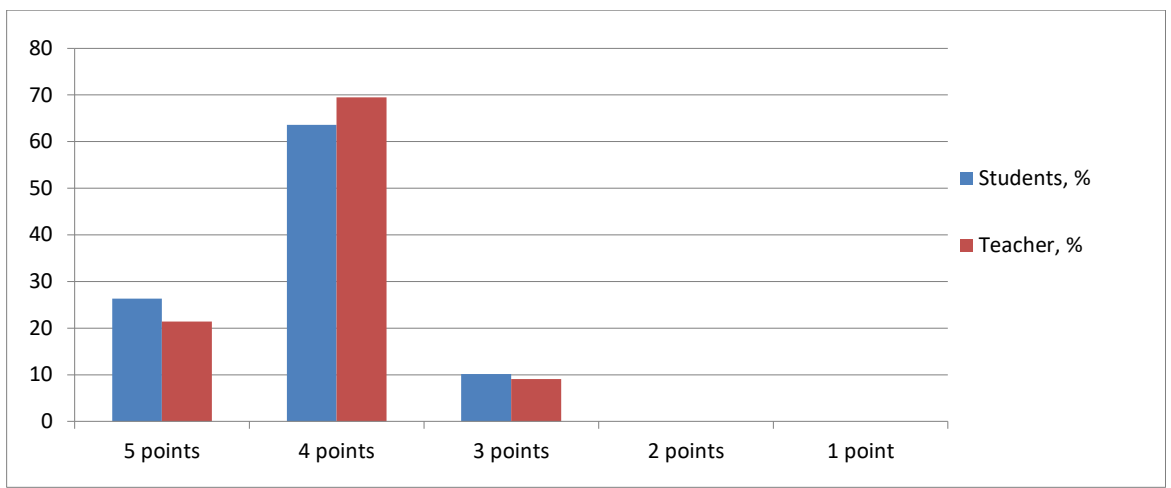

Figure 1. The ratio of assessments made by students from the second experimental group and a teacher

Table 1. Descriptive statistics on the estimates made by students from the first experimental group and a teacher

\begin{tabular}{|l|c|c|c|c|}
\hline Ratings (criteria) & $\begin{array}{c}\text { Students, } \\
\text { people }\end{array}$ & Students, \% & Teacher, \% & Difference, \% \\
\hline 5 points & 11 & 26.3 & 21.4 & -4.9 \\
\hline 4 points & 28 & 63.6 & 69.5 & +5.9 \\
\hline 3 points & 4 & 10.1 & 9.1 & -1 \\
\hline 2 points & - & - & - & - \\
\hline 1 point & - & - & - & - \\
\hline
\end{tabular}

In the second group, the majority of assessments also received 4 points (74.6\%). However, the aforementioned deviation is more than $14 \%$, which suggests that the second group students were not objective enough regarding the work made by other participants of the experiment. This also applies to other grades; for example, a deviation for 5 points student and teacher's assessments is more than $7 \%$. More than that, a deviation of 3 points is $21.6 \%$ (Figure 2, Table 2 ).

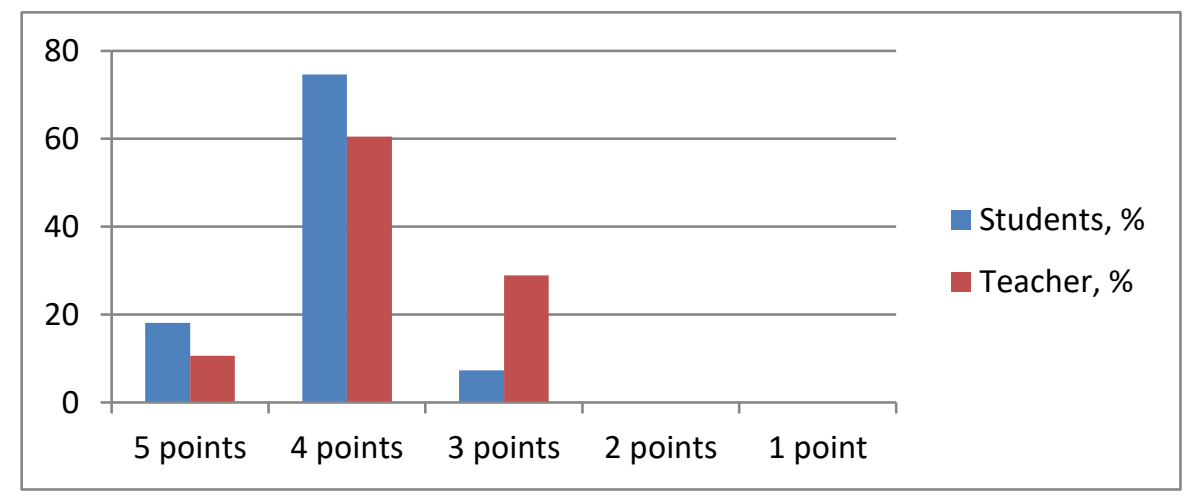

Figure 2. The ratio of assessments made by students from the second experimental group and a teacher 
Table 1. Descriptive statistics on the grades given by students from the second experimental group and a teacher

\begin{tabular}{lcccc}
\hline Ratings (criteria) & Students, people & Students, \% & Teacher, $\%$ & $\begin{array}{c}\text { Difference, } \\
\%\end{array}$ \\
\hline 5 points & 8 & 18,1 & 10,6 & $-7,5$ \\
4 points & 31 & 74,6 & 60,5 & $-14,1$ \\
3 points & 3 & 7,3 & 28,9 & $+21,6$ \\
2 points & - & - & - & - \\
1 point & - & - & - & - \\
\hline
\end{tabular}

Results of the second stage of my experiment show that the students who do not have skills for objectively evaluating the learning activities of their fellow students often underestimate or overestimate others (Table 3), but they also often overestimate themselves (this effect was also manifested during business games). Many students, receiving an assessment from others, respond as "mirrors" or randomly, without worrying about objectivity, and our experiment confirms this. (That's why, it is important to develop assessment criteria of the highest quality, and it is imperative to introduce peer assessment, peer review, and peer commenting). Some students negatively perceive such type of assessment, suspecting fellow practitioners in incompetence or deliberate aggression.

Table 2. Deviation degrees in assessment indicators made by students of the first and second experimental groups

\begin{tabular}{lccc}
\hline $\begin{array}{c}\text { Ratings } \\
\text { (criteria) }\end{array}$ & $\begin{array}{c}\text { First group students, } \\
\%\end{array}$ & $\begin{array}{c}\text { Second group } \\
\text { students, \% }\end{array}$ & Deviation, \% \\
\hline 5 points & $-4,9$ & $-7,5$ & $-2,6$ \\
4 points & $+5,9$ & $-14,1$ & $-8,2$ \\
3 points & -1 & $+21,6$ & $+20,6$ \\
\hline
\end{tabular}

My analysis of questionnaires aimed at identifying students' attitudes towards the method of peer assessment demonstrated a growing assessment of the utility of using this method. In particular, more than half of all students gave 7 points or higher to the method itself (on a 10-point scale), and only a third of them rated it from 1 to 5 points. Of course, the use of this method has a positive effect on the learning process. In particular, our students learn new topics better, get experienced in critical thinking, learn to provide their peers with quality feedback, and take responsibility for their 
assessment activities. Of particular importance is "peer commenting," especially when there is a solid justification for this assessment.

I have also established an interesting effect of applying the method of peer assessment. In short, experimental groups did not perform their tasks very well, but they showed a good understanding of the very problem being discussed in a text, capturing its essence better with the application of peer assessment! This indicates, in my opinion, the high importance of critical thinking in teaching.

Thus, my statistical data analysis and objective review of the results obtained led to a number of conclusions. Using the method of peer assessment in the process of teaching students of non-linguistic specialties is characterized by special efficiency. I conclude that one can solve a number of pedagogical problems while using this method. In particular, it is about increasing responsibility and autonomy of students; providing a deeper understanding of the subject; developing learning skills; stimulating each student to become an active worker and appraiser; developing critical thinking, etc. In addition, the method of peer assessment focuses on the maximum involvement of students in the learning process, which contributes to better learning motivation. More than that, develops of a supportive learning environment where students could feel comfortable and fully trust each other and the teacher.

\section{Conclusion}

The research presents a stand-alone empirical case, analyzing whether the method of peer assessment could be used in teaching text summarization in English. In order to address one of the most researched topics in contemporary pedagogical science and contribute to the existing body of knowledge, I decided to particularly focus on those students who are not studying linguistic specialties. The empirical part of my research was conducted at the National Research University Higher School of Economics (Moscow, Russia), with a group of undergraduate students studying at the Faculty of Economics. The conducted research clearly demonstrates the effectiveness of using the method of peer assessment in teaching text summarization in English to the students of non-linguistic specialties.

\section{References}

Anufrieva, N. V. (2002). Self-control technology in the system of developmental education. In Developmental education technologies: a collection of scientific papers (pp. 17-45). St. Petersburg, Russia.

Arlashkina, O. V. (2018). Application of the method of mutual evaluation in management training. Bulletin of the Nizhny Novgorod University named after N.I. Lobachevsky, 2(50), pp.132-141.

Belyaeva, I. S. (2013). The method of "peer review" as an integral part of the communication-oriented technology of teaching a foreign language in a non-Linguistic university. In Monitoring the quality and content of education in schools: Materials of the scientific and practical conference (pp. 21-24). Tver, Russia.

Bojko, T. V. (2012). Problems in the system of evaluating the educational activities of students in a particular university. In N. A. Zaichenko (Ed.), Education Management (pp. 72-74). St. Petersburg, Russia. 
Butakova, S. M. (2006). Organization of students' evaluation activities as a condition for developing their cognitive motivation (Dissertation of the Candidate of Pedagogical Sciences). Krasnoyarsk, Russia.

Carless, D. (2015). Excellence in university assessment: Learning from award-winning practice. London, UK: Routledge.

Dacun, N. N. (2015). Joint assessment of students' activities in mass open online courses: a systematic review of the literature. World of Science, 3, 10-11.

Dacun, N. N., \& Kopylov, N. R. (2018). Mutual evaluation and its embedding in MOODLE. Moscow, Russia.

Deller, Sh., \& Price, C. (2007). Teaching other subjects through English (resource books for teachers). Oxford, UK: Oxford University Press.

Den, A. (2012). Formation of educational and cognitive competence in teaching foreign language students to read at foreign language universities: on the material of the Korean language (Dissertation of the Candidate of Pedagogical Sciences). St. Petersburg, Russia.

East, M., \& Keson, J. (2010). MYP assess text: International baccalaureate organization. New York, NY. Facione, N., \& Facione, P. (1994). Holistic critical thinking scoring rubric text. Millbrae, CA: California Academic Press.

Falchikov, N., \& Boud, D. (2007). Rethinking assessment in higher education. London, UK: Routledge.

Harchenko, V. S. (2017). Mutual review in university courses. Higher Education in Russia, 2, 86-92.

Hedge, T. (2007). Teaching and learning in the language classroom text. Oxford, UK: Oxford University Press.

Krasnoborova, A. A. (2010). Criteria assessment as a technology for the formation of educational and cognitive competence of students (Dissertation of the Candidate of Pedagogical Sciences). Perm, Russia.

Krasnova, T. I. (2003). Evaluation of student's learning activities. Analytical Review of International Trends in the Development of Higher Education, 6, 45-53.

Larionova, M. V. (2011). Comparative analysis of the experience of evaluating the research potential of universities. Bulletin of International Organizations, 1, 4-28.

Moskaleva, I. S. (2016). Factors affecting the successful acquisition of a foreign language by students of a non-Linguistic university. Modern Research in the Field of Teaching Foreign Languages in a NonLinguistic University, 5, 107-115.

Rea-Dickins, P., \& Germaine, K. (2003). Evaluation text. Oxford, UK: Oxford University Press.

Sadler, P. M., \& Good, E. (2006). The impact of self- and peer-grading on student learning. Educational Assessment, 11(1), 1-31.

Siemens, G., \& Tittenberger, P. (2009). The handbook of emerging technologies for learning. Retrieved from

https://www.bucks.edu/media/bcccmedialibrary/documents/academics/facultywebresources/Hand book_Emerging-Technologies.pdf

Walsh, T. (2014). The peer rank method for peer assessment. In Proceedings of the Twenty-First European Conference on Artificial Intelligence (pp. 909-914). Amsterdam, The Netherlands: IOS Press.

Zhurko, V. I. (2010). A methodological basis for assessing the quality of education in higher education. News of the Russian State Pedagogical University named after A.I. Herzen, 126, 136-146. 